\title{
RFID Based Grain and Oil Products Traceability* and Its Computer Implementation
}

\author{
Haiyan $\mathrm{Hu}^{1,2, * *}$ and Yunpeng $\mathrm{Cu}^{1{ }^{1,2}}$ \\ ${ }^{1}$ Key Laboratory of Digital Agricultural Early-warning Technology, Ministry of Agriculture, \\ The People's Republic of China 100081 \\ ${ }^{2}$ Agricultural Infornmation Institute of Chinese Academy of Agriculture Science, \\ Beijing 100081, P.R.China, \\ Tel.: +86-10-82106263; Fax: +86-10-82106263 \\ huhaiyan@mail.caas.net.cn
}

\begin{abstract}
Food safety is a widely concerned problem in current world. Traceability technology is an effective measure to solve the problem. This paper describes the study of the traceability of grain and oil products. Include the study contents, and a system we developed for traceability of grain and oil products, and the demonstration of the study. The system we developed was used in Luhua group and some supermarkets and get good feedbacks.
\end{abstract}

Keywords: RFID, traceability, grain and oil products.

\section{Introduction}

China is a type of plant based country. The major grain and oil products like wheat, rice, soybean and peanuts are widely consumed in China, and played a dominant role in people's diet. The quality of grain and oil concerned hundreds of millions of people's health, and economic development and social stability. So how to enhance grain and oil quality and safety management, rectify and standardize the market has now become the most important issue of grain and oil management.

The main grain and oil products have mainly three types of hazard sources, Chemical Hazards, Biological Hazards and Physical Hazards. "Traceability" can be divided into three parts: tracking, upward traceability and downward traceability according to the type of traceability behavior, traceability can also be divided into passive and active traceability. Traceability includes external and internal traceability, External traceability means the traceability among each node in the food chain, and internal traceability means the traceability inside an enterprise or an organization.

* The study was supported by the national 863 project named the study of global traceability technology of major grain and oil products quality, the number of the project is 2006AA $10 \mathrm{Z} 268$.

** Corresponding author.

D. Li and C. Zhao (Eds.): CCTA 2009, IFIP AICT 317, pp. 400 406, 2010.

(C) IFIP International Federation for Information Processing 2010 
In recent years, the United States, Japan, Australia and other developed countries, and the European Union have taken a lot of positive measures in food safety traceability and put them into practice.

Since China joined WTO, profound changes happened in food production and circulation area. The Ministry of Agriculture launched experimental work of urban agricultural products quality control system, and focus on the quality of agricultural products traceability system construction (Lin Ling, Zhou Deyi, 2005). In 2002, Beijing Vegetable Products quality traceability system experimental project, launch by the Ministry of Agriculture, used uniform packaging and product tag code; Shanghai Animal Husbandry Department put forward Shanghai animal immunity identification management method, and set up files for pigs, cattle, sheep and other livestock products (Cheng Hao, 2007), Nanjing, Tianjin and Shenzhen have also launched traceability system construction (Fan Hongping etc.,2007). The traceability system construction of food safety is at its initial stage in China (Chang Xiang, 2007). And So far, there is no traceability system about grain and oil products in China.

\section{Implementation of the Traceability of Grain and Oil Products}

\subsection{The Goal of the Research}

The goal of the research is to make a series of breakthrough on key technologies of grain and oil products traceability. Develop a number of hardware and software with independent intellectual property rights, and demonstrate these products in grain and oil production bases, warehouses, and markets, so find a Chinese characteristic way and establish the grain and oil traceability system in China.

\subsection{The Research Route}

Fig. 1 shows the route of the research. The research includes 5 parts:

1. The general framework design of major grain and oil products traceability; 2 . The coding identification and global files digitalization of grain and oil products; 3 . Study of key technologies of global traceability; 4 . The integration of key technologies and platform; 5 . The demonstration. All the works can be divide into three stages: framework design, system design and system implementation.

\subsection{The Key Problems We Solved in the Study}

\subsubsection{Study of the Framework of the Global Traceability of Grain and Oil Products}

Based on HACCP (Hazard Analysis and Critical Control Point) and FMECA (Failure Mode Effect and Criticality Analysis), to confirm the hazard sources and Influencing factors of grain and oil products ${ }^{[1]}$, and establish their key control points, find the key indicator of the traceability, and finally, construct the unit of the traceability. 


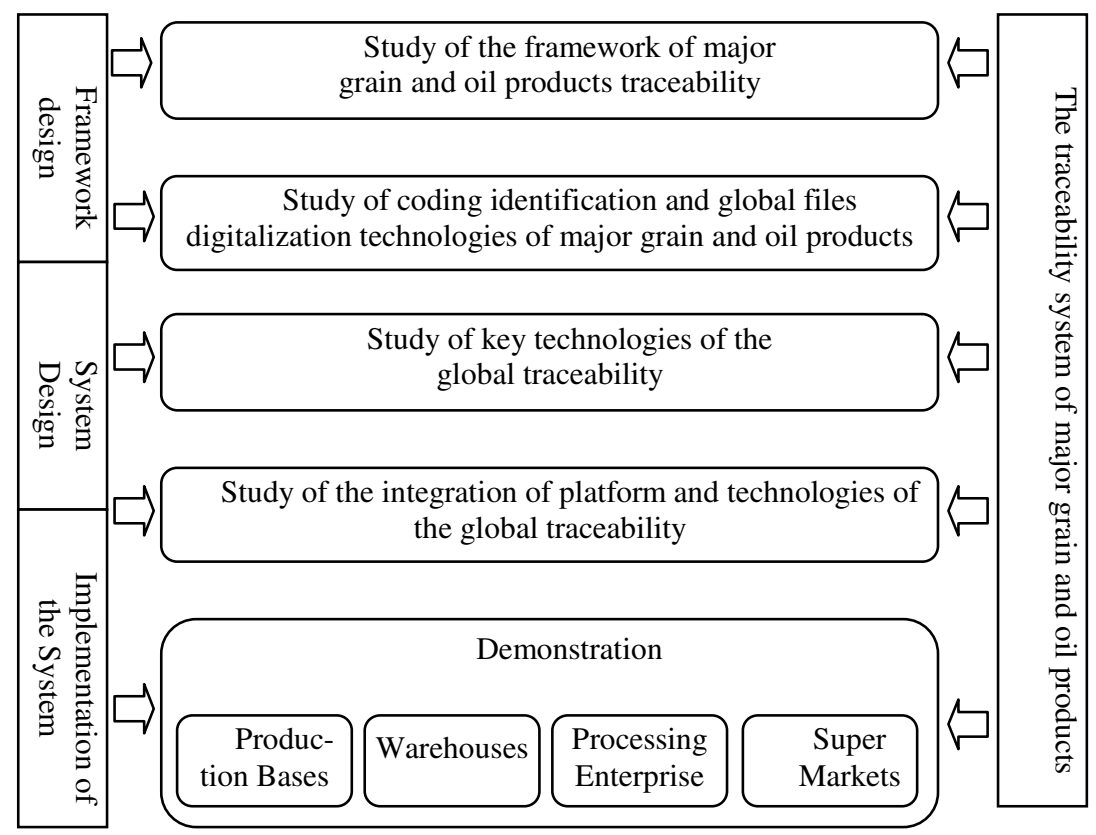

Fig. 1. The route of the research

\subsubsection{Study of Coding Identification and Global Files Digitalization Technologies of Major Grain and Oil Products}

We designed a major grain and oil products traceability classification and encoding standard, to implement the RFID (Radio Frequency Identification) based unique product identification. Based on the unique global code, we can construct the global digital files system to help the enterprises implement the digital management on production, processing, marketing and other aspects. In order to improve the data transfer rate, we use high frequency RFID to save the product information. Based on XML heterogeneous data conversion technology, we implement the data integration of external traceability and internal traceability, so the digital files of the grain and oil products chain can be exchanged transparently.

\subsubsection{Study of Digital Products and Origin Authentication}

Based on RFID digital certification, we implement the grain and oil products origin authentication. We implemented the digital origin information management through distributed database technology. We established a grain and oil products base database, to save the enterprises and origin related environment quality information, such as enterprise digital authentication certificate, the natural environment information and production environment information. 


\subsubsection{Study on RFID Middleware of Major Grain and Oil Products}

We use web services architecture to implement the information delivery and filtration and RFID message aggregation between data collection layer and application layer, and RFID events management based event notification and subscribe.

We made a RFID data describe standard, a data accuracy requirement and a data format specification and RFID data layer interface standard, developed a series of RFID based middleware, established RFID database, so constructed a RFID data management system, and implemented XML based data exchange.

\subsubsection{Study of Application Support Technologies of Traceability}

According to the hazard sources, we use agent technology to monitor the KPI (key performance indicator) of the system, so the system can make rapid reaction and report for quality accident of grain and oil products. Through MEP (Message Exchange Pattern) based information exchange technology, the key traceability information and the complete report can be delivered to different user in time.

\section{Implementation of the Grain and oil Products Traceability System}

According to the study contents above, we developed a complete traceability system. the systems include 4 subsystems (Fig.2).

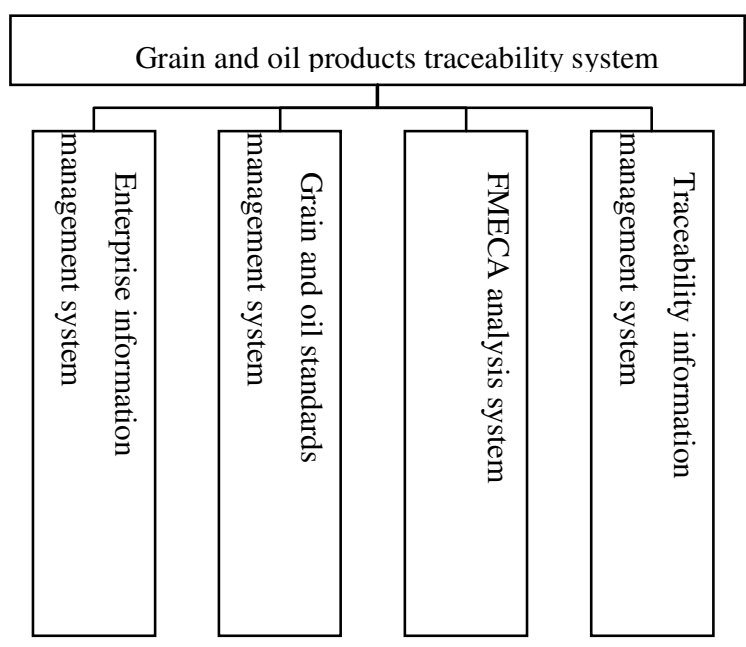

Fig. 2. The functional modules in the traceability system

Fig. 3 is the portal of the traceability system. From this homepage, user can visit the related information, and navigate to the subsystem, subscribe related information through RSS, and retrieve the traceability information inside the application. 


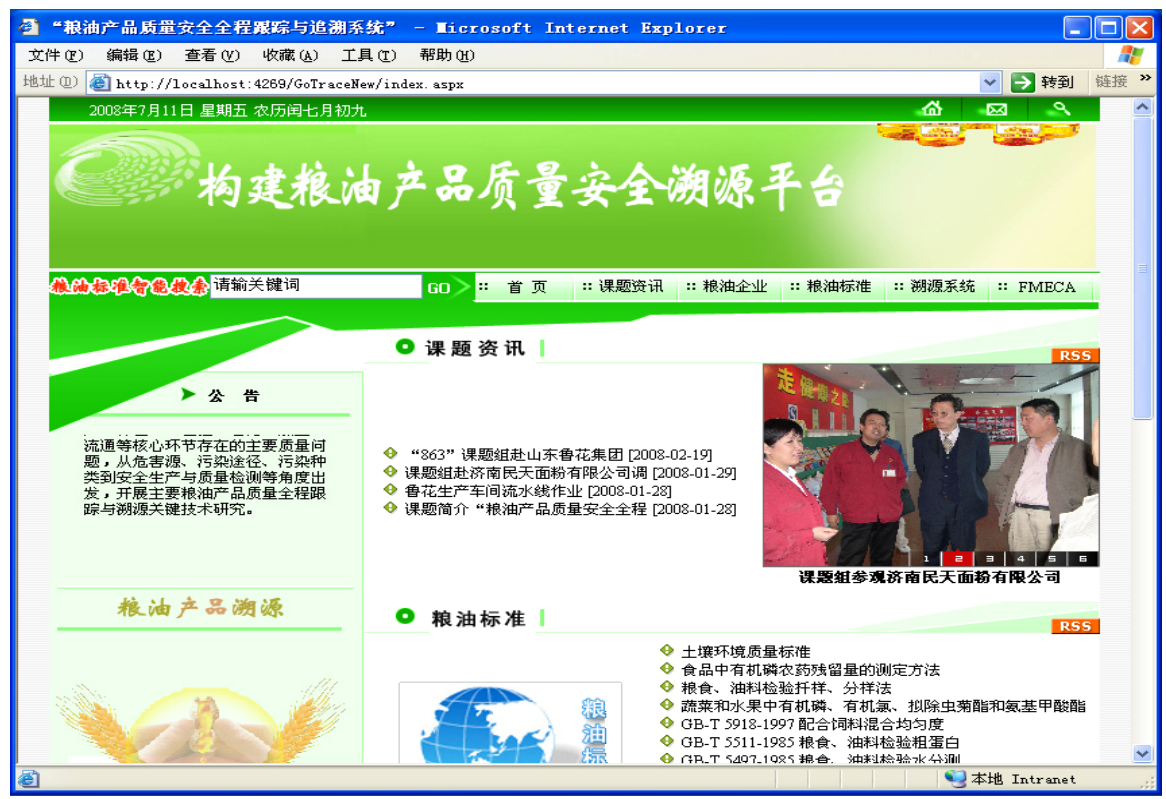

Fig. 3. The portal homepage of the system

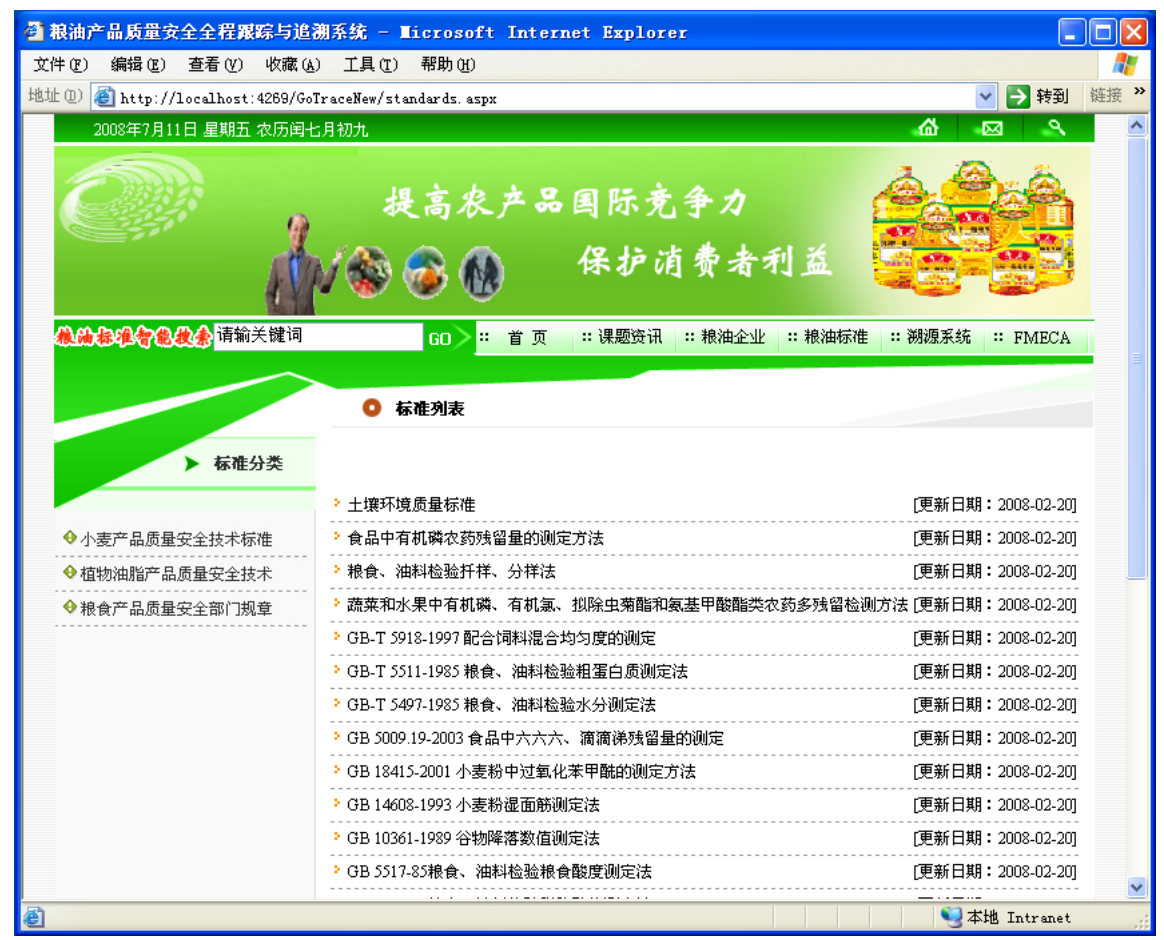

Fig. 4. The standards management system in the traceability system 
Fig. 4 is the interface of the standards management system. In this system, user can retrieve, browse, and publish the related standards.

Fig.5 is the expert points function page of FEMCA analysis system. Experts can evaluate the basis of the traceability, the features of every phase, the control measure, and give every indicator a score.

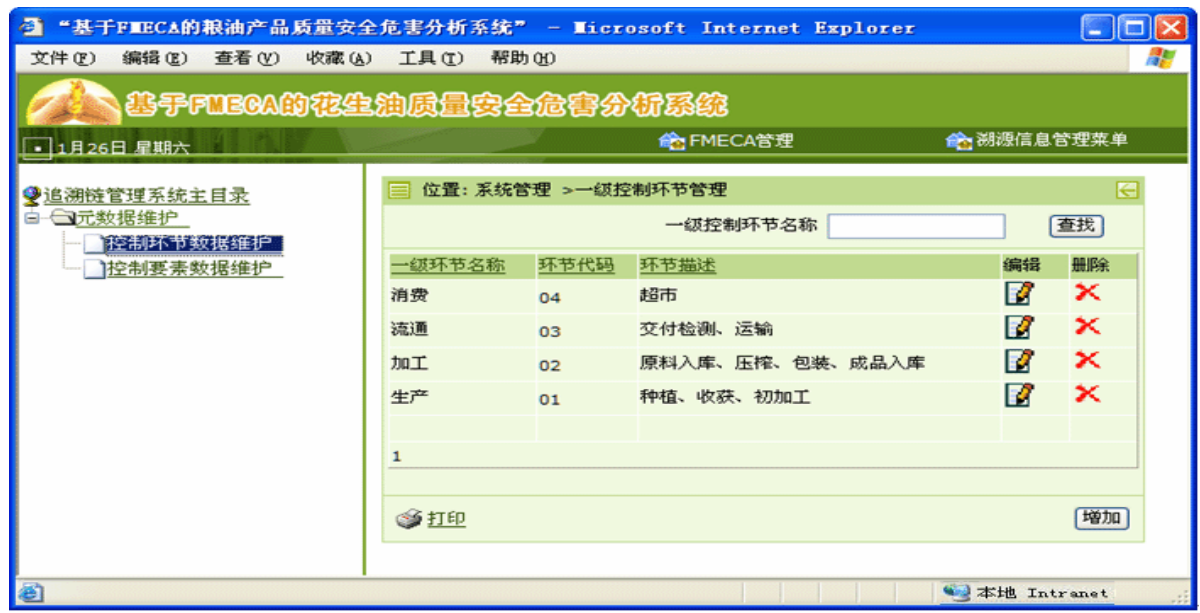

Fig. 5. The expert points function of FEMCA analysis system

Fig. 6 is the traceability metadata management page of FEMCA system, which can define, modify, and delete the metadata used in traceability. These metadata will be used in every phase to describe the features of every product.

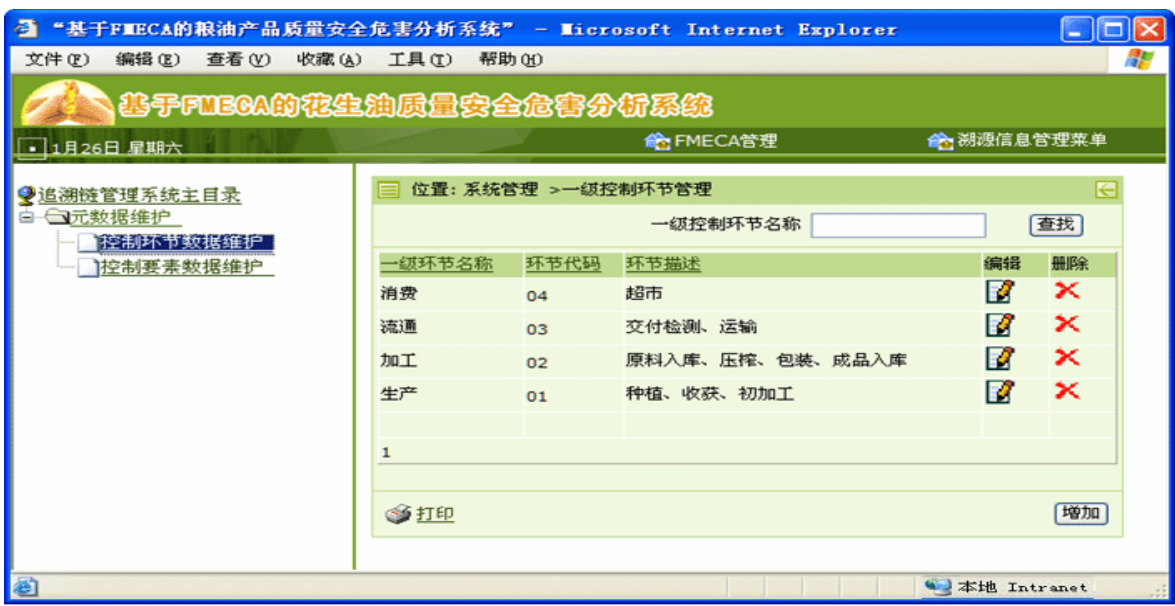

Fig. 6. Traceability metadata management sub-system 
We also developed a terminal to support the mobile application of the system, user can visit the system and query related traceability information through mobile devices.

\section{Conclusion and Outlook}

The study of grain and oil products traceability technology and its implementation is a strong measure to monitor grain and oil products quality. The system can manage the global traceability information, locate the hazard source. For consumers, it provides a way to find the related products information in every phase of the product production, process, and delivery etc.

Now, the system was used in Luhua group (a famous oil manufacture enterprise in China), and some supermarkets. The consumers expressed great curiosity to the system, and many consumers said it's a good idea to ensure food safety.

Because the production and consume chain of grain and oil products is very long, and the implementation involved many aspects, so the traceability of grain and oil products is very difficult to implement. So, the government, the enterprises and related organizations should promote the traceability of grain and oil products together, to ensure the implementation of the traceability, and finally, promote the food safety process in china.

\section{References}

Ling, L., Deyi, Z.: On the Construction of Food Quality and Safety Traceability System. Commercial research (21), 41-44 (2005)

Hao, C.: Animal product safety control and traceability technologies. Modern Agriculture science and technology (13), 169-170 (2007)

Hongping, F., Zhongze, F., Ling, Y., Aisheng, R.: Appliance and Discussion of Traceability System in Food Chain. Ecological Economy 17(4), 30-33 (2007)

Xiang, C.: Three food quality and safety traceability systems for Beijing Olympic games will be put into use in August, http: / /www. chinanews. com.cn / (July 09, 2007)

Chunhua, L., Shihong, L.: The status quo of FEMCA used in food security traceability. Food and Nutrition in China (6), 7-10 (2008) 